\title{
GRUZINSKI, Serge. A águia e o Dragão - Portugueses e Espanhóis na globalização do século XVI.
}

\author{
Edições 70, Lisboa, 2015. Tradução de Pedro Elói Duarte
}

Izabel Maria dos Santos*

Palavras-chave: América Colonial; Colonização ibérica; Representação; Século XVI.

Key-words: Colonial America; Iberian colonization; Representation; Century XVI.

Velho conhecido dos estudiosos que se dedicam às investigações no campo das mentalidades, o historiador Serge Gruzinski, ratifica o seu interesse pelas sociedades coloniais da América e pelo intenso encontro de culturas que têm lugar neste cenário, e traz à público mais uma instigante análise na qual se debruça sobre as dinâmicas sociais e culturais que se engendraram no contexto da colonização ibérica na América com o seu novo livro, lançado no Brasil em 2015, intitulado A águia e o dragão - ambições europeias e mundialização no século XVI. O historiador francês, caudatário da Escola do Annales, tem alinhado suas pesquisas à uma perspectiva multidisciplinar da História, trabalhando em conjunto com outros campos das ciências humanas, como por exemplo a Antropologia, e incorporando à sua análise não só as fontes escritas, mas também as iconográficas, como podemos constatar em seus últimos volumes publicados, tais como: Les Quatre parties du monde. Histoire d'une mondialisation; Quelle heure est-il là-bas ? Amérique et islam à l'orée des temps modernes; L'Histoire, pour quoi faire?.

Devemos ainda ressaltar que o seu trabalho critica a concepção eurocêntrica da historiografia tradicional e se ancora na perspectiva da Conected Histories ${ }^{1}$, rechaçando qualquer tipo de comparação simplista que se apegue ao local em detrimento do total. Sua tentativa, portanto, seria a de demonstrar a convivência entre as múltiplas realidades sócio-culturais e suas mais variadas dinâmicas de interação, sem perder de vista a relação entre micro e macro. Diante disso, $A$ águia e o dragão, se propõe a entender a inserção dos ibéricos no processo de mundialização, através da análise comparativa entre a atuação do embaixador de Portugal na China do imperador Zhengde e a atuação de Hernan Cortés no México-Tenochtitlan, junto à Montezuma e, portanto, pode ser considerada uma obra vinculada à perspectiva da História Global, já que tenta “juntar as peças do jogo mundial desmembradas pelas historiografias nacionais ou pulverizadas por uma micro-história mal dominada" (p.354).

\footnotetext{
*Mestre em História da Arte, Património e Turismo Cultural pela Universidade de Coimbra. Atualmente é doutoranda em História pela Faculdade de Letras da Universidade de Coimbra. Contato: Faculdade de Letras da Universidade de Coimbra, Largo da Porta Férrea - 3004-530 Coimbra, Portugal.
} 
O livro desvenda os caminhos de portugueses e espanhóis naquilo que o autor chama de "globalização do século XVI", perscrutando as dinâmicas internas da China e do México no alvorecer do século e analisando como se deu o contato desses povos com os ibéricos. Com efeito, o autor defende que a maneira como os acontecimentos se desencadearam contribuiu, decisivamente, para que fosse fundado o "ocidente euroamericano", e afirma que embora a presença dos ibéricos nos territórios referidos não tenha sido de fato programada, também não foi ao acaso e deve ser vista como fruto de uma dinâmica comum ao contexto da época, que inseria os reinos na lógica da expansão marítima com vistas na exploração das "molucas", as conhecidas ilhas de especiarias. Além disso, o autor desmistifica a ideia de que os pioneiros no processo da expansão marítima europeia tenham se lançado rumo ao desconhecido e afirma que, embora houvesse grande confusão nas noções de Ocidente e Oriente, já havia, nessas sociedades, uma certa percepção do espaço marítimo, tanto devido à experiência acumulada com as navegações desde o final do século XV, quanto devido ao conhecimento dos escritos de Marco Polo.

Posto isto, podemos dizer que a tese do autor é a de que o comportamento e as atitudes políticas de Tomé Pires junto ao império de Zenghde, bem como de Hernan Cortés junto ao império de Montezuma, simultaneamente ao posicionamento e contexto das autoridades locais da China e do México, foram determinantes para que o primeiro empreendimento incorresse em fracasso e o segundo tivesse sucesso. Assim, essa conjuntura teria traçado o destino da China e, nesse caso, a falência do projeto colonizador português na área, bem como teria delineado a sorte do Méxicotenochtitlan, que seria dominado e colonizado pelos espanhóis. Portanto, o autor defende que a interação entre esses povos acabou sendo responsável pelo destino que lhes aguardava e que as condições locais que se engendraram a partir desse contato foram responsáveis pelo triunfo ou derrota dos objetivos dominantes, objetivos estes, vale ressaltar, amplamente voltados para o comércio de especiarias. Nesse sentido, para Gruzinski, essas teriam sido as circunstâncias fulcrais que levaram ao processo de interligação dessas partes do mundo - Ásia, América e Europa através de circuitos comercias que as ligariam intensamente e que marcariam a viragem dos europeus para o Oeste e a fundação do que ele chama de "ocidente euroamericano".

Nessa perspectiva, o livro em questão se trata de um profundo e estimulante estudo a respeito das características das sociedades chinesa e mexicana do século XVI e da interação do mundo ibério com estas populações. $\mathrm{O}$ autor consegue, à medida que vai demonstrando a sua tese, explorar a forma de organização e administração da China e do México, explicando como o contato inicial desses povos com portugueses e espanhóis, respectivamente, foi pacífico e logo descambou 
para o conflito e o que ele chama de "choque de civilizações", resultando no domínio e colonização no caso dos mexicas e na resistência e expulsão, no caso dos chineses. Ao percorrer este caminho, o autor consegue esclarecer o processo de decodificação do outro nesse espaço de convivência, afirmando que enquanto os chineses não tinham nenhum interesse em identificar o intruso que para eles se tratava de mais um bando de piratas de nacionalidade desconhecida, os mexicas, por outro lado, tinham urgência em compreender o seu agressor, pois disso dependia, em certa medida, a sua capacidade de resistir.

Em contrapartida, os ibéricos tentavam distinguir o outro para melhor concretizar seus anseios de conquista e, segundo o autor, comprovaram que a falta de conhecimento inicial não se constituía como uma barreira intransponível e, nesse sentido, se esforçavam para se adaptar à língua, ao clima, à alimentação e etc, na tentativa de construir atalhos que facilitassem a compreensão da lógica social e cultural daquelas sociedades. Uma vez que esses aspectos foram mapeados e resultaram na consciência das fraturas políticas do adversário, os ibéricos se aproveitaram deles na tentativa de concretizar o domínio. No México, a identificação das intensas rivalidades entre as cidades devido à falta de unidade política foi decisiva para que o domínio e colonização tivesse sucesso, já na China, o diagnóstico do descontentamento local devido à rigidez do sistema imperial não foi suficiente para que a empreitada ibérica tivesse êxito.

Obviamente, este diagnóstico não se resumia às questões políticas, econômicas e sociais, havia também o espantoso encontro de culturas completamente distintas, que a partir dali iriam se misturar e se modificar simultaneamente. Esse encontro deu margem para que os estranhos mundos se representassem concomitantemente, daí uma série de conhecimentos serão difundidos na Europa acerca dessas civilizações, tanto a chinesa, quanto a mexicana. $\mathrm{O}$ autor, ressalta, porém, que enquanto as informações sobre o México são divulgadas desde o início do processo de colonização, aquelas referentes à China só irão se propagar pela Europa a partir de meados do século XVI. Segundo o autor, esse fenômeno poderia ser atribuído, entre outras coisas, ao fato de que a China não era completamente desconhecida por parte dos ibéricos, devido às relações comerciais existentes naquela região, já o México é um mundo completamente novo a se descortinar e causou grande reboliço ao ser descoberto, acabando por motivar imenso fascínio. Os documentos escritos que cumprem o papel de nos dar um retrato daquilo que seriam a China e o México no limiar do século XVI são: a Suma Oriental de Tomé Pires e as cartas de Hernan Cortés.

Segundo o autor, os ibéricos ficaram espantados ao perceberem que, tanto na China quanto no México, os povos contavam com a existência do livro, e isso teria sido determinante para que se 
moldasse uma imagem positiva na Europa sobre esses povos, já que o livro, para as culturas letradas, é um marcador de civilização. Do outro lado, porém, existe uma notável dificuldade para invocar representações da Europa feitas por estes povos, em primeiro lugar, no caso da China, devido à sua pouca abertura, pela falta de interesse em conhecer o seu inimigo, considerado apenas como um forasteiro. Já no caso do México, mesmo com o grande interesse e curiosidade pelos europeus, por não haver testemunhos escritos de uma visão pessoal do ameríndio, estes, se um dia existiram, não sobreviveram ao tempo.

Dessa maneira, se constituíram as imagens que se firmariam ao longo do tempo como fundadoras daquilo que viriam a ser as civilizações mexica e chinesa. As cartas de Cortés seriam amplamente divulgadas e, segundo o autor, familiarizariam a cristandade com os esplendores do México e com a representação das glórias da conquista, estas serão eternizadas no imaginário universal. Em contrapartida, embora não tenham sido alvo de larga divulgação, a descrição feita por Tomé Pires acerca da China, traz uma visão, de acordo com Gruzinski, mais assertiva a respeito das características dessa sociedade, pois seria um diagnóstico feito do interior dessa sociedade, enquanto que o relato de Cortés seria uma visão panorâmica e, portanto, superficial. Ainda assim, o fato é que mesmo diante de todas estas questões “a epopeia dos conquistadores e o destino fatal do império Asteca continuariam a fascinar, enquanto a descoberta da China dos Ming e o fracasso de Tomé Pires nunca interessaram muita gente" (p.106).

Acreditamos que a obra ultrapassa os limites de sua tese central e acaba por se transformar num manual de história do México e da China, ao qual se pode recorrer para sanar dúvidas pontuais a respeito da organização e administração política, social e cultural dessas sociedades. Nesse sentido, acreditamos que o livro não só cumpre com o seu objetivo precípuo, como também transborda erudição. Para aqueles leitores que não têm grande formação a respeito do Oriente, a quantidade de informações novas pode representar alguma dificuldade, mas com o desenrolar das páginas o leitor passa a se familiarizar com os nomes e os acontecimentos analisados no texto e, ao final da leitura, percebe-se o ganho de uma noção panorâmica acerca das civilizações em questão. $\mathrm{O}$ livro consegue ir além da temática do choque cultural entre portugueses/chineses e espanhóis/mexicas e nos leva por outros caminhos dessa história, pelos meandros da organização interna dessas sociedades.

Como não poderia deixar de ser, a obra traz uma discussão bem fundamentada, ancorada, como já afirmamos aqui, nas perspectivas da Connected Histories e da História Global e, assim sendo, rejeita a historiografia tradicional que concebe a Europa como centro do mundo, procurando 
demonstrar que esse papel protagonista no processo de globalização do século XVI - embora, paradoxalmente, não possa ser negado, visto que foram os ibéricos os atores principais - não se deu simplesmente devido à graça e talento destes homens, mas foi sim, em grande medida, impulsionado e delimitado pelos contextos e dinâmicas que se apresentavam na época. Diante disso ao autor afirma que "a imagem de um avanço inevitável dos europeus, quer se enalteça as suas virtudes heroicas e civilizadoras, quer o votemos ao desprezo, é uma ilusão que teima em persistir. Decorre de uma visão linear e teleológica da História, que continua associada à pena do historiador e ao olhar do seu leitor" (p.40).

Isto posto, vale salientar ainda que, o autor trava diálogo com a historiografia clássica e a mais atualizada, tradicionalmente competente e de referência na temática pertinente à Expansão Ultramarina europeia. Entre os autores com os quais dialoga estão Francisco Bethencourt, Sanjay Subrahmanyam e Charles Boxer. As fontes elencadas permitem demonstrar a sua tese. Ele recorre às cartas e aos relatos de viagem de homens como Cristovão Colombo, Pietro Martire d'Anghiera, Bernal Diaz del Castillo e, obviamente, Hernan Cortés e Tomé Pires, entre outros. Contudo, ao longo do texto, o próprio Gruzinski, deixa claro a deficiência de sua obra no que diz respeito às questões da representação europeia feita pelos indígenas e/ou chineses, afirmando que para tal estudo não existem fontes, pois estas, quando existem, são limitadas pela influência direta do domínio europeu e até da conversão ao cristianismo e, portanto, não exprimem uma visão pessoal a respeito dos ibéricos. Ou, nos demais casos, sequer existem, pois não resistiram ao tempo. Esse obstáculo não prejudica o trabalho, visto que o seu debate central não está circunscrito a esta temática especificamente.

Com efeito, uma outra característica que contribui efetivamente para o alcance dos objetivos do livro, é, sem dúvida a organização de sua estrutura. $\mathrm{O}$ autor, opta por uma estrutura que não separe as análises referentes à China, daquelas referentes ao México, pelo contrário, ele dispõe as discussões de maneira a fazer com que o leitor perceba que elas são complementares e a sua visão em separado acarretaria em prejuízo no entendimento total da obra. Os capítulos, por sua vez, são dispostos de modo a guiar o leitor através dos labirintos dessa história, dando-lhe, de maneira impecável, não só a nítida compreensão do argumento defendido pelo autor, mas também um excelente panorama sobre história das culturas chinesa e mexicana. Nesse sentido, não utiliza a conclusão de seu texto para expor sua tese - esta fica evidente ao longo das 373 páginas escritas mas apenas para ratificar o seu argumento. Dessa maneira, facilita o trabalho do leitor e não abre margens para confusões. 
Por último, cumpre dizer que a obra em discussão não está desconectada do tempo e do espaço e encontra lugar na produção historiográfica atual. Sua perspectiva de análise, já discutida aqui, tem notável eco na História que vem sendo desenvolvida desde finais do século passado. Nesse sentido, o autor demonstra sua capacidade de aclimatação e desenvolve um estudo que fortalece seu elo com a História da América Latina, numa análise comparada profunda e densa sobre os aspectos culturais, econômicos e sociais da China imperial e do México-Tenochtitlan, nos dando uma verdadeira lição de como se faz História em tempos de prateleiras abarrotadas de romances históricos acríticos e fantasiosos.

1 SUBRAHMANYAM, Sanjay. "Connected Histories: Notes towards a Reconfiguration of Early Modern Eurasia", Modern Asian Studies, v. 31, n. 3, 1997, pp. 735-762. 